\title{
LA INSTALACIÓN ARTÍSTICA Y EL USO DE LAS TICS COMO SOPORTE COMUNICACIONAL EN LA PRESENTACIÓN DE INVESTIGACIÓN EN CIENCIAS SOCIALES
}

\author{
A instalação artística e o uso das TIC como suporte comunicacional na \\ apresentação de pesquisas em ciências sociais
}
The artistic installation and the use of the TICs as a support communication in the presentation of research in science social

Marina Tamara Roman Universidad de Buenos Aires, Universidad Nacional de las Artes (UNA), Escuela Superior de Educación Artística "Manuel Belgrano tammroman@gmail.com

Paula Rodríguez Universidad Nacional de las Artes (UNA), Escuela Superior de Educación Artística "Manuel Belgrano" paulagrod@gmail.com

\section{Resumen}

Este dossier reflexiona sobre la posibilidad de una práctica artística como soporte comunicacional para la presentación de investigaciones en el campo de las ciencias sociales, en este caso en particular la presentación de resultados de investigación de proyectos sobre la Historia de las Industrias Culturales en la Argentina. Articular contenido de estudio y soporte expresivo resulta un complemento significativo para la promoción del conocimiento. Los procesos de producción discursiva requieren de modalidades artístico-culturales que tengan en cuenta los nuevos formatos creativos surgidos en la expansión de las TICs, en este sentido la experiencia da cuenta de una Instalación Artística que combina diferentes lenguajes expresivos para contar la historia del tango, de la industria editorial, de empresarios multimedia y memoria e Historia en la Argentina en el Siglo XX y XXI.

Palabras claves: Instalación Artística. Comunicación. Nuevas Tecnologías.

\section{Resumo}

Este dossiê reflete sobre a possibilidade de uma prática artística como suporte de comunicação para a apresentação de pesquisas no campo das ciências sociais, no caso em particular a apresentação dos resultados de pesquisas de projetos sobre a História das Indústrias Culturais na Argentina. Articular o conteúdo do estudo e o apoio expressivo é um complemento significativo para a promoção do conhecimento. Os processos sociais de produção discursiva exigem modalidades artístico-culturais que levem em conta os novos formatos criativos que surgiram na expansão das TICs, neste sentido a experiência mostra uma instalação artística que combina diferentes linguagens expressivas para contar a história 
do tango, da indústria editorial, de empreendedores multimídia e memória e História da Argentina nos séculos XX e XXI.

Palavras chave: Instalação artística. Comunicação. Tecnologías novas.

\begin{abstract}
This dossier reflects on the possibility of an artistic practic as a communication support for the presentation of investigations in the field of social sciences, in this particular case the presentation of research results of projects about the History of the Cultural Industries in Argentina. Articulate study content and expressive support result a significant complement for the promotion of knowledge. Discursive production processes require artistic-cultural modalities that take into account the new creative formats that have arisen in the expansion of ICTs, in this sense the experience reveals an Artistic installation that combines different expressive languages for tell the story of tango, the publishing industry, multimedia businessmen and Memory and History in Argentina during the 20th and 21st centuries.
\end{abstract}

Keywords: Artistic Instalation. Communication. New Technologies.

\title{
INTRODUCCIÓN
}

Este dossier reflexiona, a partir de una experiencia interdisciplinaria plasmada en una instalación artística, sobre la posibilidad de una práctica artística como recurso/soporte comunicacional para la presentación de investigaciones en el campo de las Ciencias Sociales, en este caso en particular la exposición de resultados de investigación de proyectos sobre la Historia de las Industrias Culturales en la Argentina.

Las líneas de investigación que comprenden dichos proyectos articulan diferentes disciplinas tales como: la Historia, la Economía, las Artes Visuales y Sonoras y la Comunicación.

Dicho evento se denominó "Más de un siglo de producciones y consumos culturales en Argentina" y se llevó a cabo en el Complejo Histórico Cultural denominado Manzana de las Luces durante la primera semana de septiembre de 2017 en la Ciudad de Buenos Aires, en él se expuso el resultado de las indagaciones llevadas a cabo a partir de tres Proyectos de Investigación pertenecientes dos a la Universidad de Buenos Aires y uno a la Universidad Nacional de Tres de Febrero.

En el marco de esta reflexión se desarrolla una breve reseña de la instalación artística como práctica estética contemporánea y su articulación como recurso/soporte comunicacional para la exposición de diversos contenidos. Se aborda el concepto de comunicación desde una perspectiva relacional y dentro de esta disciplina se presentan un conjunto de acciones y 
productos que se utilizaron como estrategia comunicacional de promoción e invitación al evento mencionado.

\section{LÍNEAS DE INVESTIGACIÓN}

Los proyectos participantes fueron: Las Empresas Culturales y los Proyectos de Cultura en el marco del desarrollo de las nuevas tecnologías de la información y de la comunicación. Análisis desde la Historia Económica (CEEED - Facultad de Ciencias Económicas - UBA); Memoria, identidad y consumo. La irrupción de las industrias culturales en la reinvención de la memoria y la construcción de identidad en la Argentina contemporánea (Ciclo Básico Común - UBA) y El sector cultural en Argentina: empresas, industrias y proyectos culturales. Su desarrollo histórico - económico en el marco del nuevo paradigma tecnológico (UNTREF).

Ellos se concentran en el estudio de Empresas de Cultura, Industrias Culturales y Proyectos de Cultura en las diferentes esferas de producción y consumo de bienes y servicios de ese sector. El equipo de investigación conformado a partir de los Proyectos está integrado por académicos formados en diversas disciplinas. Con ellos se comenzó a transitar la senda de la renovación en las formas de difusión y comunicación de resultados.

De esta manera, se decidió que el formato de instalación artística -un espacio colectivo de sonidos y materiales visuales/ audiovisuales al que se le propone un recorrido social y simbólico por parte de la audiencia- era el recurso adecuado para comunicar a un público amplio y variado, los avances del trabajo académico por parte de los investigadores.

Desde esta perspectiva, se realizó una particular apropiación de la instalación artística inscribiéndola en otro contexto. No obstante, se partió de la siguiente pregunta ¿Por qué una instalación? y la respuesta estuvo en el objeto de estudio convocante: los bienes y servicios culturales se producen y se consumen desde hace poco más de un siglo desde y con la multimedia. (Román y Ruffolo. 2017: 6)

Las líneas de investigación contenidas en los Proyectos presentes en la instalación son la historia de las empresas editoriales en Argentina; la historia de la conformación temprana de multimedios en nuestro país a través de uno de sus empresarios más destacados: Max Glücksmann; la historia de la producción visual y audiovisual en el pasado reciente, vinculando Historia y Memoria; y finalmente, lo que llamamos el proceso de patrimonialización del tango durante las últimas tres décadas. 
En esta propuesta los avances en materia de investigación se comunican en todas ellas a través de la articulación estética de producciones audiovisuales, de fotografías, de sonido y de ilustraciones, como así también del relato de poemas por parte de los propios poetas irrumpiendo en la visita del público. Así la ilustración de un ascensor y todo lo que en él acontece con sus propios sonidos y el recitado de poesías grabadas y en vivo, presentan la colección Poetas en el ascensor, dando lugar a las pequeñas editoriales multimedia, siendo una de ellas Elemento disruptivo.

El devenir de las nuevas tecnologías - como la fotografía, el cine, la radio, la televisión, internet y los diversos dispositivos electrónicos - ha modificado la manera en que se producen y se consumen los bienes culturales en el cual coexisten y conviven formatos tradicionales y contemporáneos de producción cultural.

\section{LA INSTALACIÓN ARTÍSTICA}

En la elección de una instalación artística como soporte/recurso comunicacional fue importante comprender su sentido desde una perspectiva histórica.

La instalación es una experiencia estética que se desarrolla en el campo de las artes plásticas hacia la década del 60 del Siglo XX, tanto a nivel internacional como nacional. Esta nueva práctica artística tuvo lugar en un contexto histórico-social de grandes cambios, los años 60 fueron una bisagra del decurso de la historia donde se trastocaron las certezas propias de la modernidad y en la subjetividad de los artistas preparó el terreno para un nuevo arte que rompe definitivamente con los cánones clásicos.

Es importante aclarar que a lo largo del Siglo XX la historia del arte muestra los principales cambios rupturistas respecto de los tradicionales modos de crear, las vanguardias estéticas europeas de principios del Siglo XX -en particular la matriz lingüística de Marcel Duchamp con sus famosos ready-made-, las manifestaciones estéticas regionalistas en América Latina y las post-vanguardias que se desarrollan luego de la Segunda Guerra Mundial tanto en Europa como en Estados Unidos -neo expresionismo, informalismo, Land art, Earth art, arte minimalista, pop art, arte conceptual, poéticas performaticas de Joseph Beuys- son el germen de nuevos modos de expresión, de comunicación, de lenguaje, de uso de materiales y de espacios de interacción social y artística. 
En particular en la década del 60 en la Argentina, estos nuevos modos de crear y de mostrar también se desarrollaron en múltiples experiencias estéticas cuyos efectos se prolongan hasta la actualidad.

\begin{abstract}
Es necesario entonces decir que el Instituto Di Tella -que ocupó un importante espacio en aquella década- tuvo mucho que ver con esta nueva situación sin olvidar la tarea del Grupo Espartaco, que uso las paredes de la ciudad como soporte de sus obras. Si por un lado los lenguajes artísticos multiplicaban sus posibilidades de elocuencia- no olvidemos que los medios masivos ya empezaban a ser teorizados como nuevos soportes, se comenzaban a hacer los primeros happenings y también estaban naciendo las primeras manifestaciones de arte conceptual- por otro, un considerable número de artistas y grupos clamaban por un arte comprometido. (Santana, 2006: 6)
\end{abstract}

\title{
ARTE Y COMUNICACIÓN
}

Articular contenido de estudio y soporte expresivo resulta un complemento altamente significativo para la transferencia del conocimiento producido. Los procesos sociales de producción discursiva requieren cada vez más de las nuevas modalidades artístico-culturales que tengan en cuenta los nuevos formatos creativos (visuales, sonoros y audiovisuales), en este sentido la experiencia que presentamos da cuenta de una Instalación Artística que combina diferentes lenguajes expresivos para contar, tal como se mencionó en párrafos anteriores, los resultados de diferentes líneas de investigación.

La elección de una Instalación Artística como presentación de nuevos conocimientos radica en que la misma permite un vínculo interactivo con el público participante haciendo de un objeto de estudio un objeto de consumo cultural.

Si bien resulta difícil reducir a una definición a la instalación artística, ya que esta se expresa de múltiples formas, sí podemos reconocer pautas o características implícitas en sus modos de presentación.

En términos generales las instalaciones se presentan como un acontecimiento que incluye al espectador y en el que se desarrolla una acción que no se limita a la mera contemplación de una imagen o un objeto sino por el contrario interpela a todo el aparato sensitivo humano, donde es posible ver, oír, sentir, tocar, oler. El público pasa a formar parte de ese acontecimiento y además requiere de su participación.

Espacio y tiempo, conceptos que atraviesan a la producción artística visual, se manifiestan en la instalación con nuevos elementos para su comprensión, o mejor dicho para su redefinición. El espacio físico es continente y contenido al mismo tiempo, es texto y 
contexto, es soporte e imagen. El tiempo es único y específico, es experiencia efímera e intransferible, se aprecia en un momento y en un lugar determinado.

Las características del espacio, el contexto, la articulación y complementariedad de múltiples elementos expresivos sumado a la interacción con el espectador conforman el acto y el hecho estético en el marco de una situación comunicacional de producción de sentidos.

Esta práctica artística aporta todo tipo de materiales, formas y procesos. Las nuevas tecnologías de la comunicación y la información, los medios audiovisuales, el auge de los diseños, atraviesan a todos los lenguajes artísticos-expresivos y los empujan a nuevos modos de hacer, sentir y ver.

Los objetos e imágenes presentes en las instalaciones además de ser mostrados se presentan como testigos de la acción para lo que fueron creados. Y en el desarrollo de esta acción la instalación también se manifiesta, en muchas de sus experiencias, como arte colectivo en el que confluyen no solo múltiples lenguajes sino también múltiples artistas.

\section{LA INSTALACIÓN COMO DISPOSITIVO COMUNICACIONAL}

Pensar entonces a una instalación artística como recurso/soporte comunicacional requiere comprender al menos, dos conceptos que se interrelacionan, el de dispositivo y el de comunicación. Hablamos de dispositivo en la medida que en la instalación como práctica artística se ponen en juego un conjunto de recursos/soportes tecnológicos y audiovisuales en un espacio y tiempo determinados que mediatizan en una situación relacional de comunicación entendida como proceso de producción de sentido social.

Silvia Vaselini, quien analiza a la instalación como dispositivo expositivo y comunicacional, explica que según el crítico de arte y filósofo belga Thierri De Duve la instalación artística es el establecimiento de un conjunto singular de relaciones espaciales entre el objeto y el espacio arquitectónico que fuerza el espectador a verse como parte de una situación creada. (Valesini. 2012: 1). La referencia a un espacio artístico entendido como ámbito de relaciones, procesos, intercambios y circulaciones entre personas, nos habla de una práctica que no presenta ninguna pretensión de pureza o especificidad de forma -más allá de la ubicación de elementos entrelazados en un espacio- tiempo-, sino más bien se caracteriza por su carácter ecléctico y diverso, distante de definiciones univocas, lo cual permite sus múltiples abordajes e interpretaciones. 
La instalación instituye un espacio significativo, al conferir al espacio/tiempo que ocupa una dignidad especial, transformándolo, a veces, incluso en contenido específico de la propuesta; paralelamente otorga el espectador, la jerarquía de articulador de la obra, no solo incluyéndolo en el espacio sino incorporándolo al proceso de la construcción representativa. (Valesini. 2012: 2)

Un dispositivo comunicacional es, conforme a Jean Pierre Meunier, una red de sentidos interrelacionados, un ordenamiento de medios en función de un fin: una entidad compleja en la que la enunciación tiene lugar: lugar en el que operan los intercambios discursivos, lugar donde se torna posible el emplazamiento social de los discursos. (Menuier. 2010: 4)

Según este autor, los hombres, a partir de sus relaciones de comunicación, construyen dispositivos de comunicación por medio de los que se estructuran sus relaciones de comunicación. Así los medios como -el cine, la televisión- son vastos dispositivos fusionales funcionando para la seducción y el consenso. Según Meunier un dispositivo de comunicación comprende al menos un ordenamiento espacial y un ordenamiento semiótico -una combinación de textos, de imágenes, de sonidos. (Menuier. 2010: 4). Estas reflexiones nos permiten dar entidad y legitimar a la instalación artística realizada como medio de transmisión de conocimientos producidos en el mundo académico.

\section{LA INSTALACIÓN Y SUS ALCANCES COMUNICACIONALES}

La instalación artística llevada a cabo fue un evento de presentación y promoción de resultados de proyectos de investigación de carácter interdisciplinario, pero el evento en si mismo también requirió del armado de una estrategia comunicacional que comprendió diferentes recursos tecnológicos y soportes gráficos para su difusión e invitación.

Toda estrategia comunicacional comprende un conjunto de acciones y recursos que colaboran en la difusión, información y comunicación de lo que se propone comunicar. En este sentido, esta instalación artística estuvo acompañada del diseño de un Afiche en papel que se colocó en diferentes instituciones educativas y culturales de la Ciudad de Buenos Aires y alrededores (Conurbano Bonaerense). También se realizó un flyer que se viralizó a través de diferentes redes sociales institucionales y personales, se diseñó un folleto impreso, se elaboró un libro compilando las diferentes líneas de investigación en el marco de los tres proyectos y por último, se realizó un audiovisual del evento como registro de la acción colectiva. 
PROGRAMA DE PÓS-GRADUAÇÃO EM COMUNICAÇÃO DA UNIVERSIDADE FEDERAL DE SANTA MARIA

El conjunto de estas acciones tuvo como finalidad promover y transferir conocimientos sobre algunos aspectos de la propia historia social, económica, artística y cultural de la Argentina. En este sentido, el arte contemporáneo desarrollado en espacios culturales públicos y el uso de las nuevas tecnologías de la información y comunicación (Tic) permitió la descentralización de la cultura y las artes hacia diferentes sectores de la sociedad y más allá de las fronteras, al mismo tiempo colaboró en la creación de procesos de construcción colectiva.

El evento duró cinco días, por su ubicación geográfica en el Centro de la Ciudad, la Manzana de las Luces, sitió histórico y museo público de la Ciudad de Buenos Aires, fue visitada por turistas nacionales e internacionales, académicos y público en general, como así también, por estudiantes de diferentes niveles educativos que en el marco de la visita al museo con guía especializada también participaron y vivenciaron la instalación artística, llevándose registro fotográfico y gráfico de lo allí expuesto.

Cada línea de investigación se presentó con diversos soportes sonoros, visuales y audiovisuales poniéndose de manifiesto la tarea interdisciplinaria que implicó el armado de esta instalación.

\section{ILUSTRACIONES}

El escenario estético tuvo como elemento visual articulador de todas las líneas de investigación un conjunto de ilustraciones con rasgos infantiles y costumbristas que presentan diferentes situaciones que hacen referencia a los productos y consumos culturales analizados. Para el diseño de estas imágenes participó una artista visual que colabora en el equipo de investigadores poniendo en imágenes sus abordajes académicos. Las ilustraciones fueron realizadas con técnica de dibujo y luego digitalizadas, impresas en vinilo y montadas en PVC, un material resistente y liviano. Esto permitió colgarlas sin dañar la decoración ni la arquitectura del lugar ya que como es un sitio histórico no era posible modificar nada de lo allí presente. Este aspecto también fue tenido en cuenta para el armado de toda la instalación. 


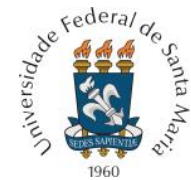

PROGRAMA DE PÓS-GRADUAÇÃO EM COMUNICAÇÃO DA UNIVERSIDADE FEDERAL DE SANTA MARIA
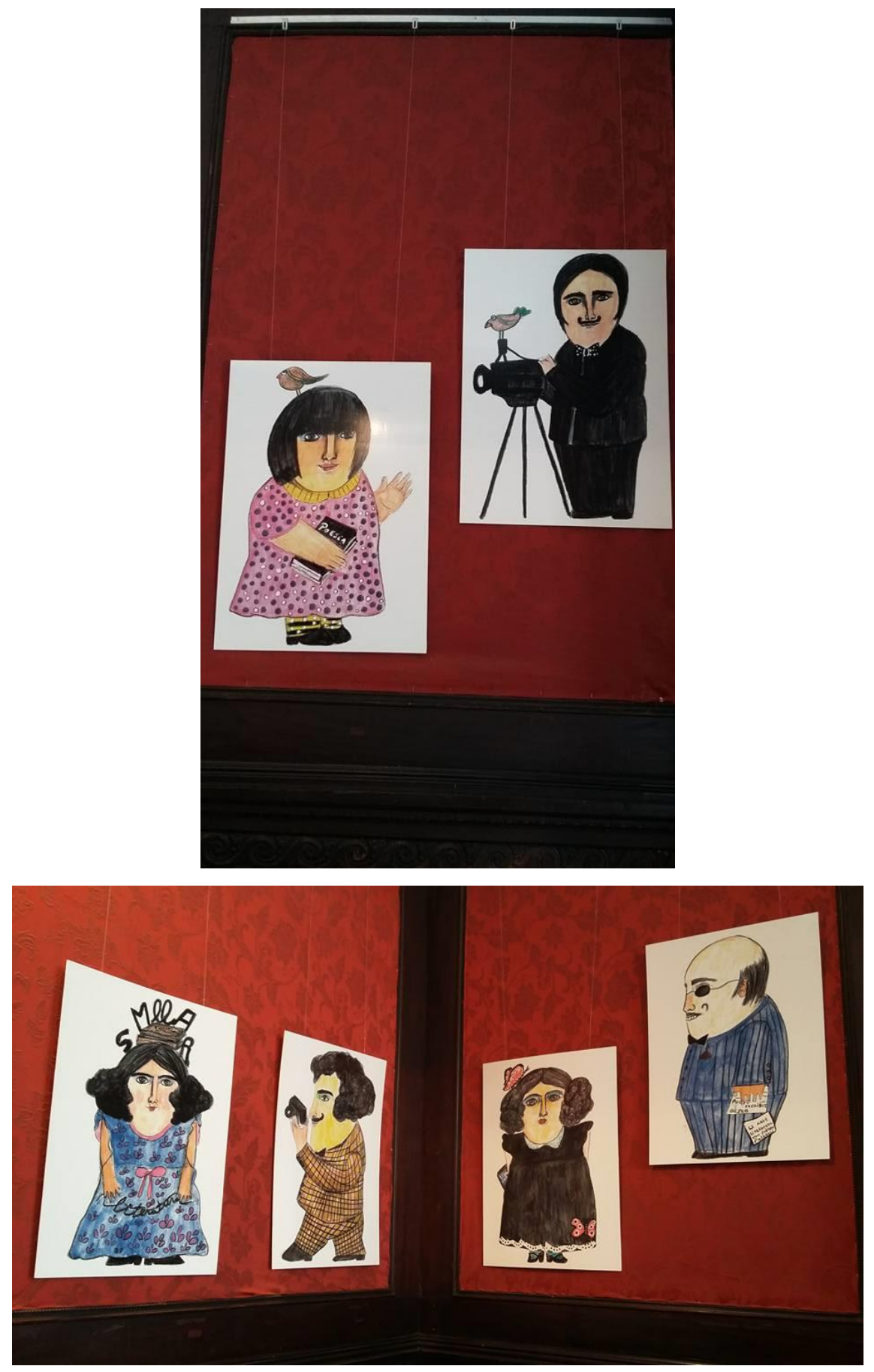

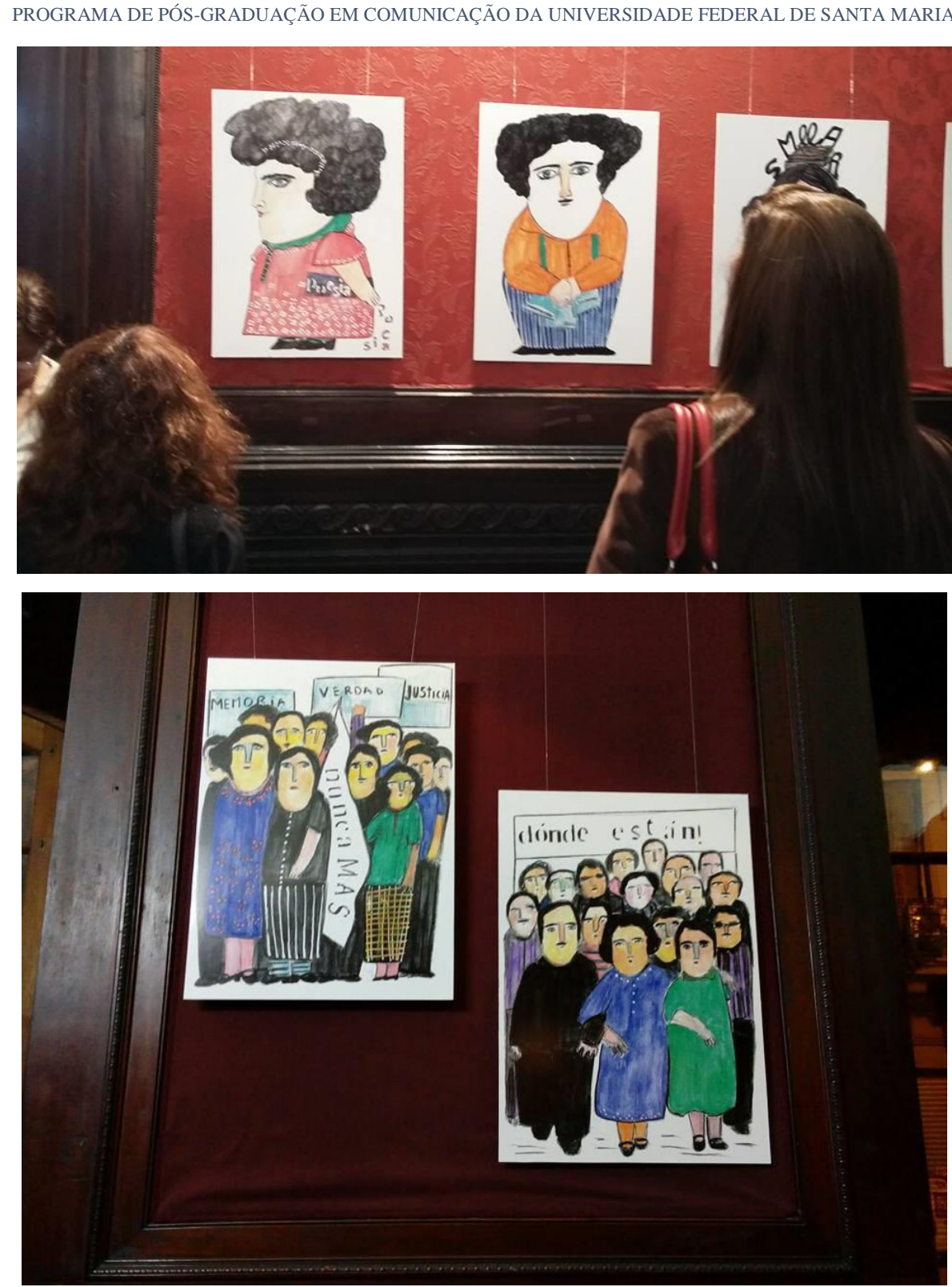

Ilustraciones en referencia a los productos y consumos culturales en relación con cada línea de investigación.

\section{HISTORIA DE LAS INDUSTRIAS EDITORIALES Y EL PRIMER EMPRESARIO MULTIMEDIA EN LA ARGENTINA}

Para la historia de las empresas editoriales y para la construcción de un proyecto multimedia en las primeras décadas del siglo XX en la Argentina se realizaron dos videos de aproximadamente 3 minutos cada uno, con una selección de imágenes y testimonios de época.

Como complemento del análisis de las empresas editoriales del video mencionado se diseño la ilustración de un ascensor, incluyendo elementos sonoros con los sonidos propios de un ascensor y el de las poesías de la colección Poetas en el ascensor de la micro editorial Elemento Disruptivo, convirtiendo este espacio en un objeto transdisciplinar en el que el todo 


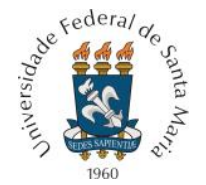

PROGRAMA DE PÓS-GRADUAÇÃO EM COMUNICAÇÃO DA UNIVERSIDADE FEDERAL DE SANTA MARIA

fue mucho más que la suma de las partes y permitió el estudio de las pequeñas editoriales multimedia apelando a múltiples sentidos.

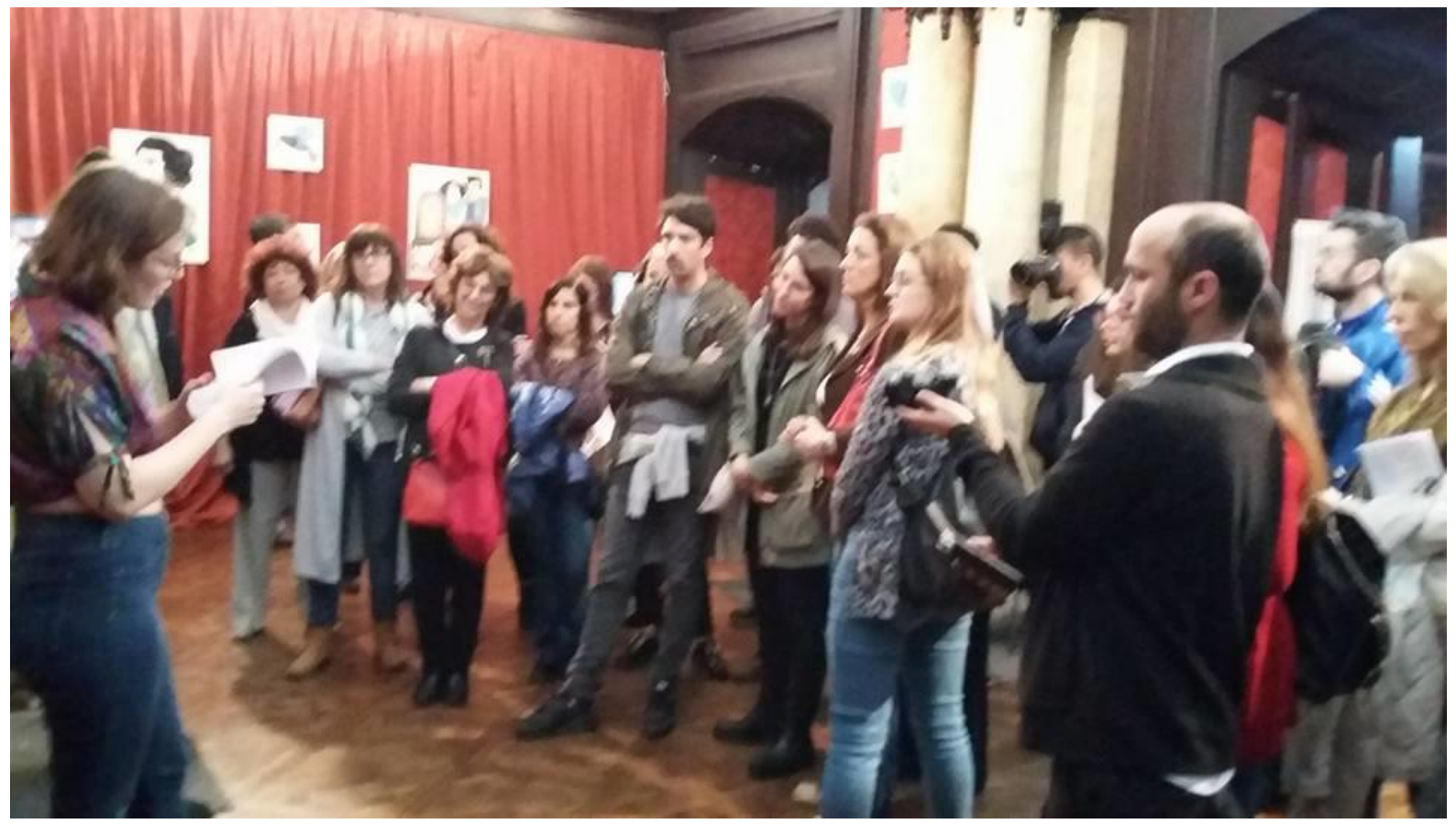

Recitando poesías de la Colección Poetas en el ascensor

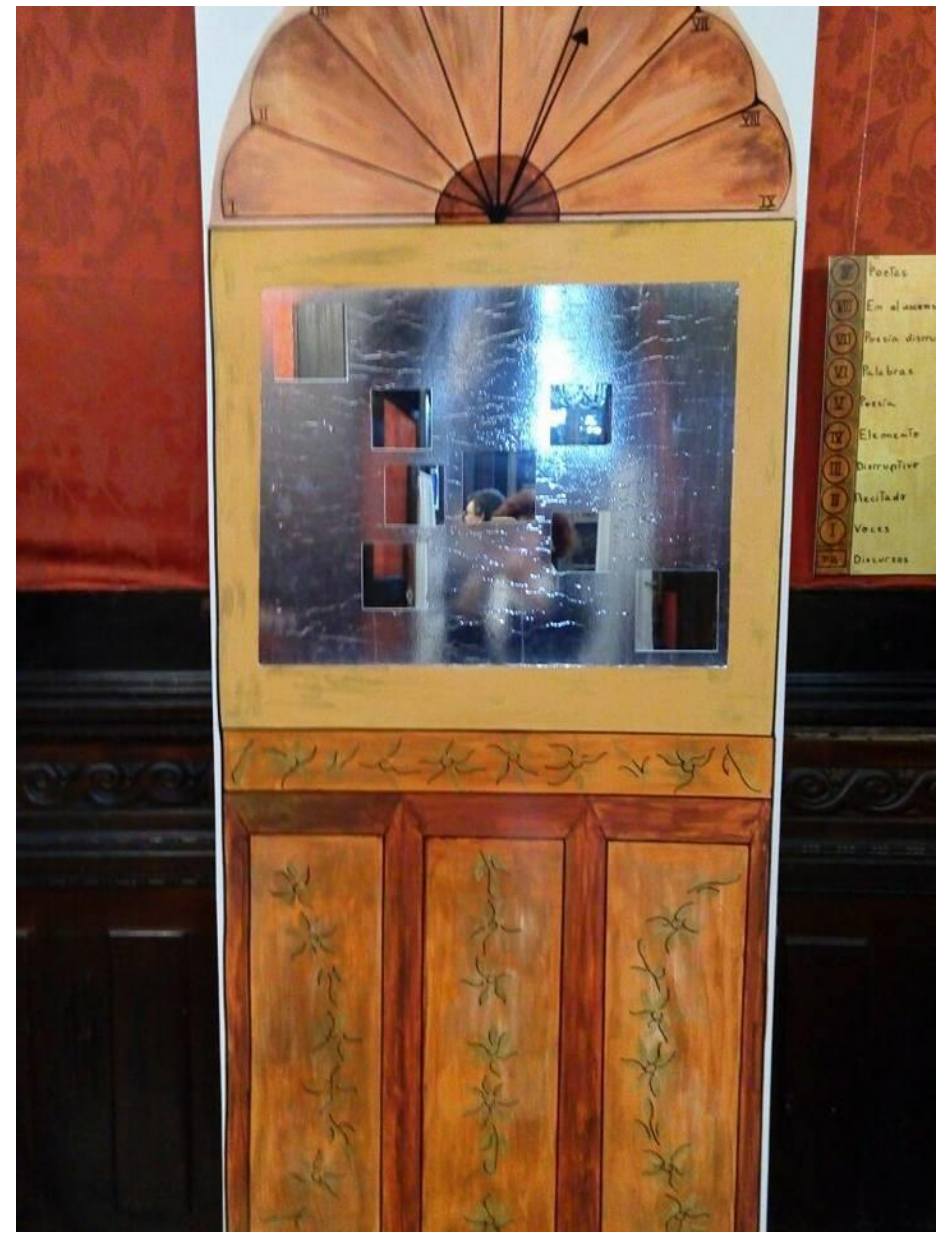

ANIMUS $\begin{aligned} & \text { Revista Interamericana de Comunicação Midiática } \\ & \text { E-ISSN 2175-4977 | v.18 n.36| } 2019 \text { | www.ufsm.br/animus }\end{aligned}$ 


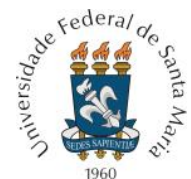

PROGRAMA DE PÓS-GRADUAÇÃO EM COMUNICAÇÃO DA UNIVERSIDADE FEDERAL DE SANTA MARIA

Escenificación de un ascensor con sonidos de ascensor y poesías recitadas

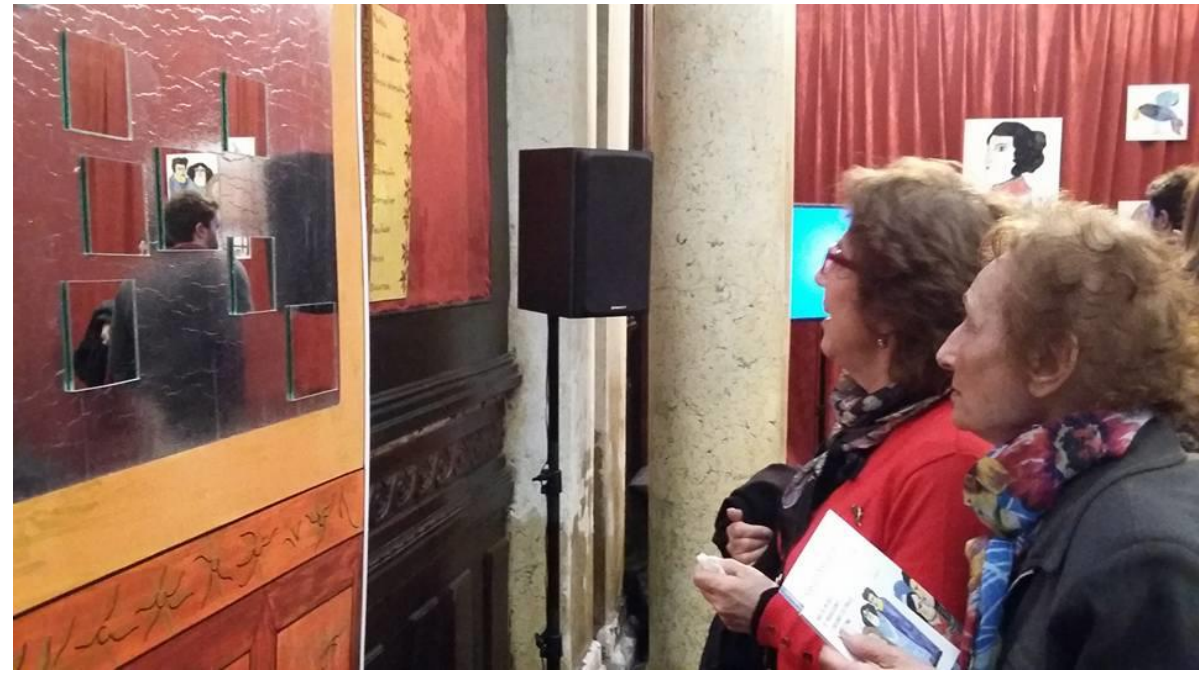

Publico escuchando la sonorización del ascensor

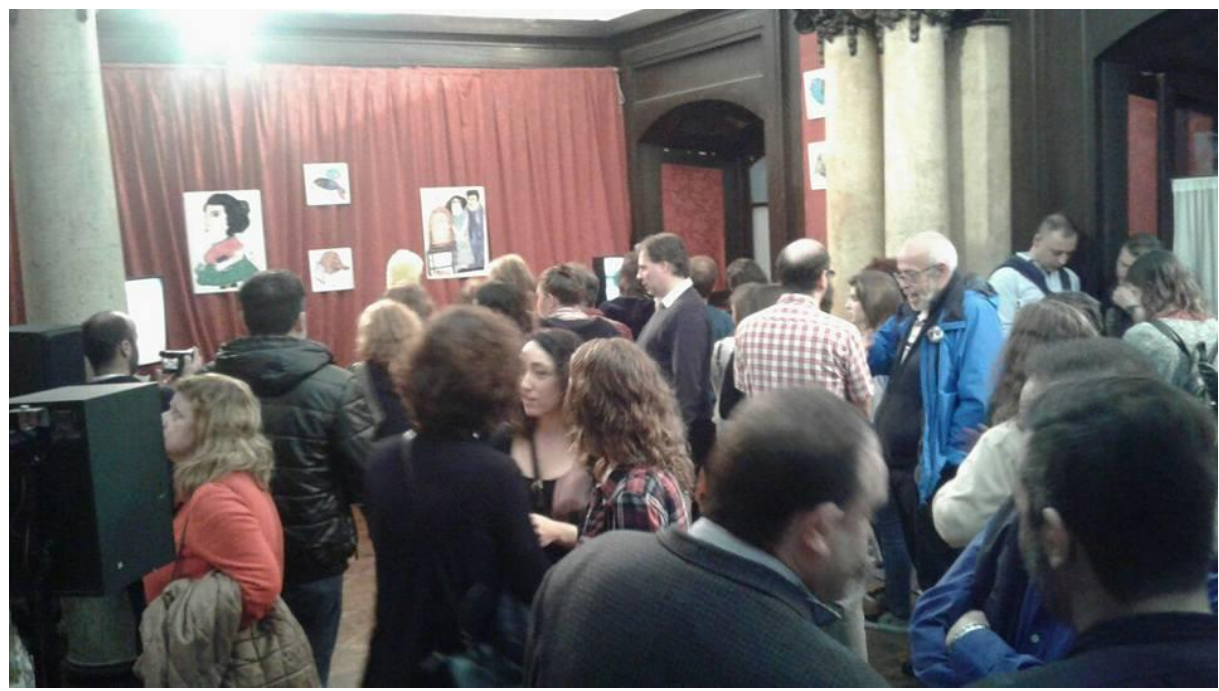

Publico visitando la Instalación Artística

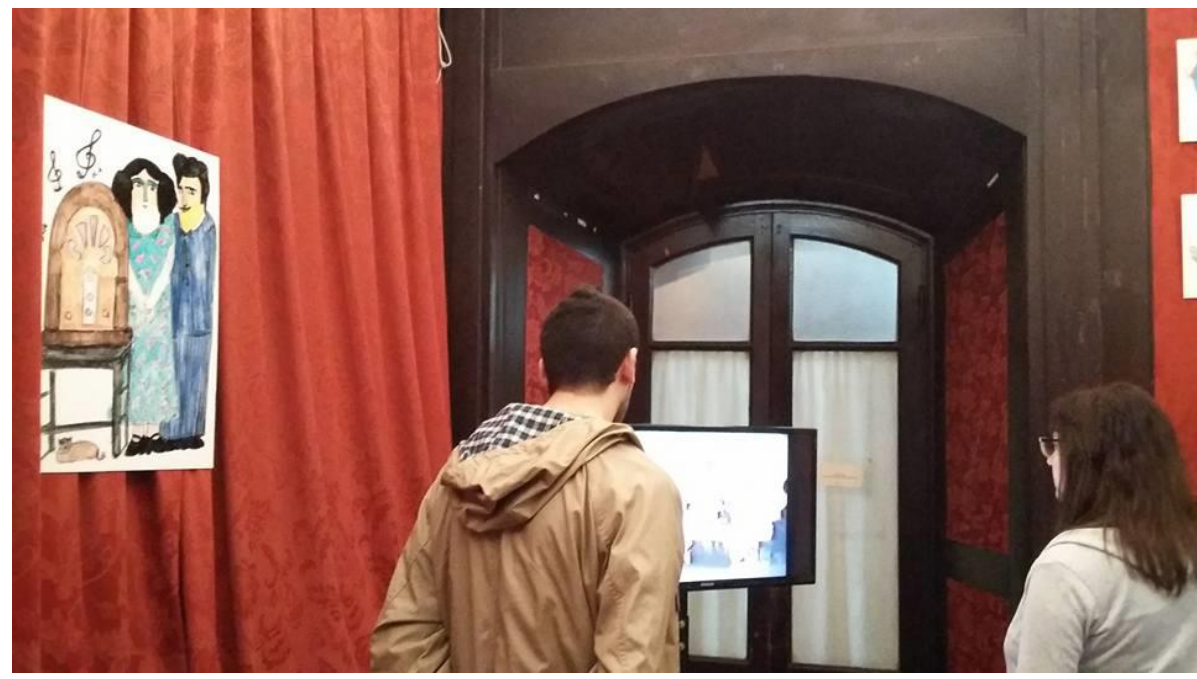

ANIMUS $\begin{aligned} & \text { Revista Interamericana de Comunicação Midiática } \\ & \text { E-15sN 2175-4977 | v.18 n.36| } 2019 \text { | www.ufsm.br/animus }\end{aligned}$ 
PROGRAMA DE PÓS-GRADUAÇÃO EM COMUNICAÇÃO DA UNIVERSIDADE FEDERAL DE SANTA MARIA

TV: proyección del video sobre la historia del primer empresario multimedia en la Argentina
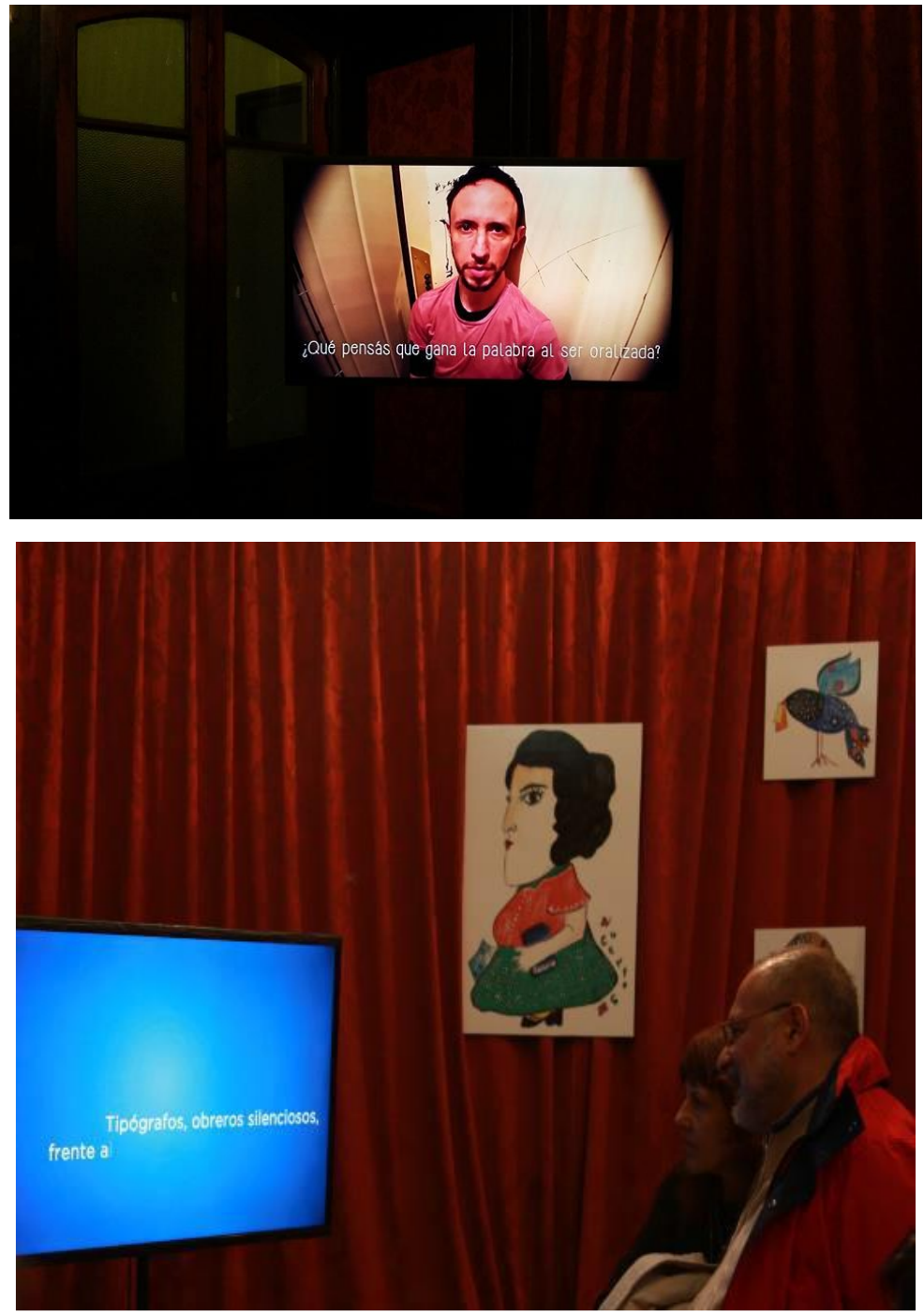

TV: video de la historia de las industrias editoriales en la Argentina

\section{EL TANGO EN LA HISTORIA RECIENTE: REPRESENTACIONES Y MIRADAS}

Para el caso de reapropiación del tango se elaboró una realización sonora que el público pudo escuchar a través de un mecanismo electrónico contenido en un tocadiscos antiguo. La idea fue expresar a partir de la intervención de un "winco" (toca disco antiguo), reproductor de vinilos caracterizado como uno de los más emblemáticos en el rubro, los diversos sonidos presentes en el tango. Se desarrolló una opción musical e interactiva que permitió compartir con quienes transitaron el evento. Esta experiencia dio la oportunidad de abrir el discurso hacia otras nuevas formas de expresión. El resultado trajo a debate la posibilidad de reflexionar sobre las apropiaciones diversas de aquello que circula, en este 
PROGRAMA DE PÓS-GRADUAÇÃO EM COMUNICAÇÃO DA UNIVERSIDADE FEDERAL DE SANTA MARIA

caso, en un formato definido: un objeto, música, y sus posibilidades de combinarla según los deseos o intereses de los participantes por medio de un mecanismo simple y sencillo.

Según lo expresado por los propios investigadores, la intención fue generar a través de un mecanismo interactivo la reconstrucción de un relato coral de la historia del pasado y el presente del tango. (Alonso. 2017: 7)

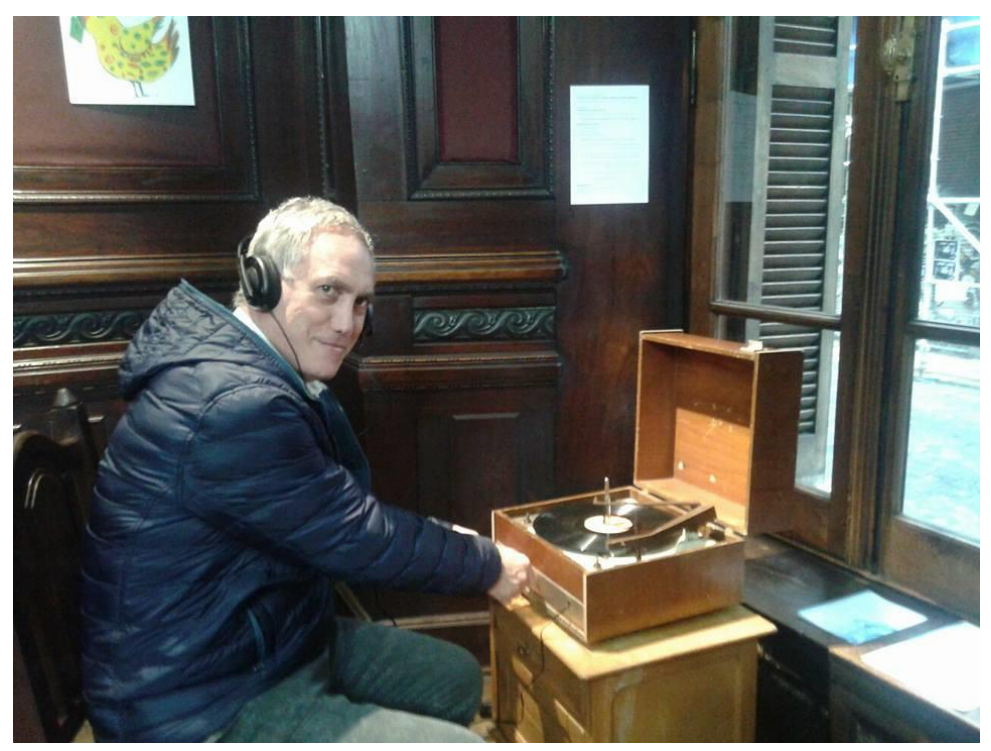

Público escuchando relatos y canciones de tango

\section{HISTORIA Y MEMORIA: EL ESPACIO APARECIDO/DESAPARECIDO EN IMÁGENES}

Para la vinculación entre Historia y Memoria en nuestro pasado reciente en imágenes se llevó a cabo una selección de fotografías de Enrique Shore y que forman parte del acervo Archivo Nacional de la Memoria. Material que fue digitalizado e indexado por la Dirección de Gestión de Fondos Audiovisuales de ese archivo. También, se exhibió el cortometraje titulado La Matanza realizado por la artista visual María Giuffra a partir de ilustraciones por ella realizadas y a través de una reconstrucción del asesinato de su padre en 1977 a manos de las FFAA argentinas presente en el expediente de una causa judicial encontrado en un archivo que perteneció a la ex dirección de inteligencia de la Policía de la Provincia de Buenos Aires, y que permaneció oculto hasta 1998. 


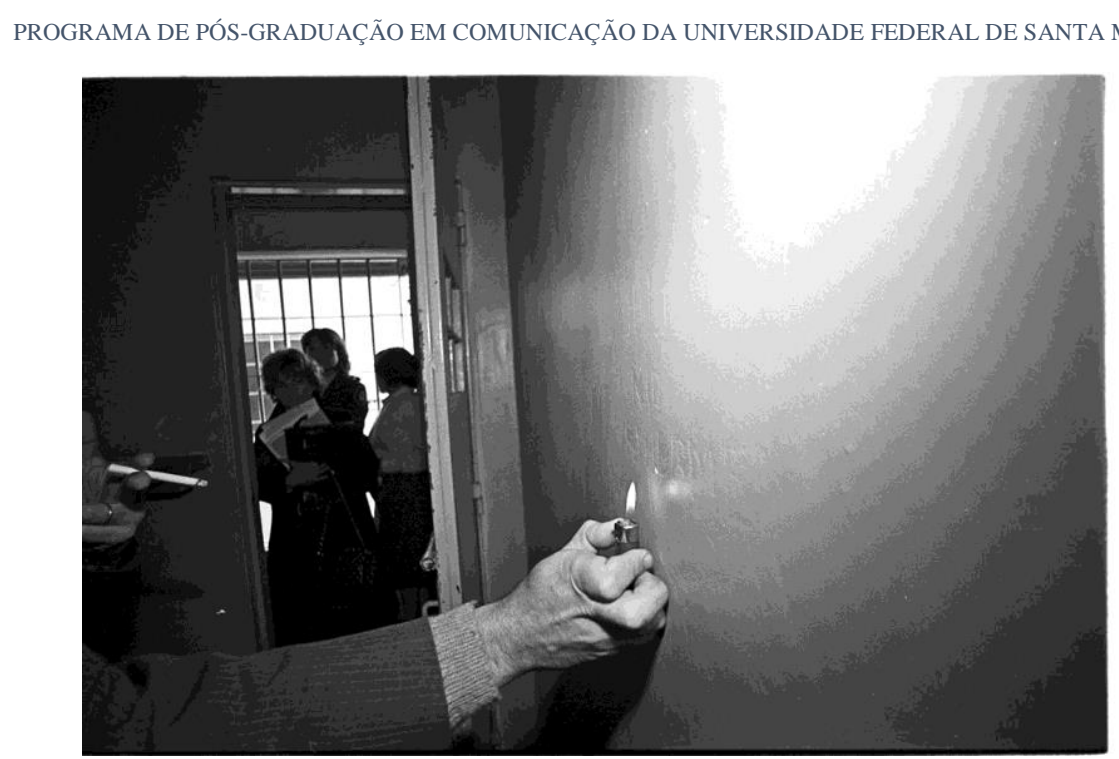

Ex Centro Clandestino de Detención, Tortura y Exterminio Pozo de Quilmes. Mayo de 1984. Provincia de Buenos Aires. Quilmes.
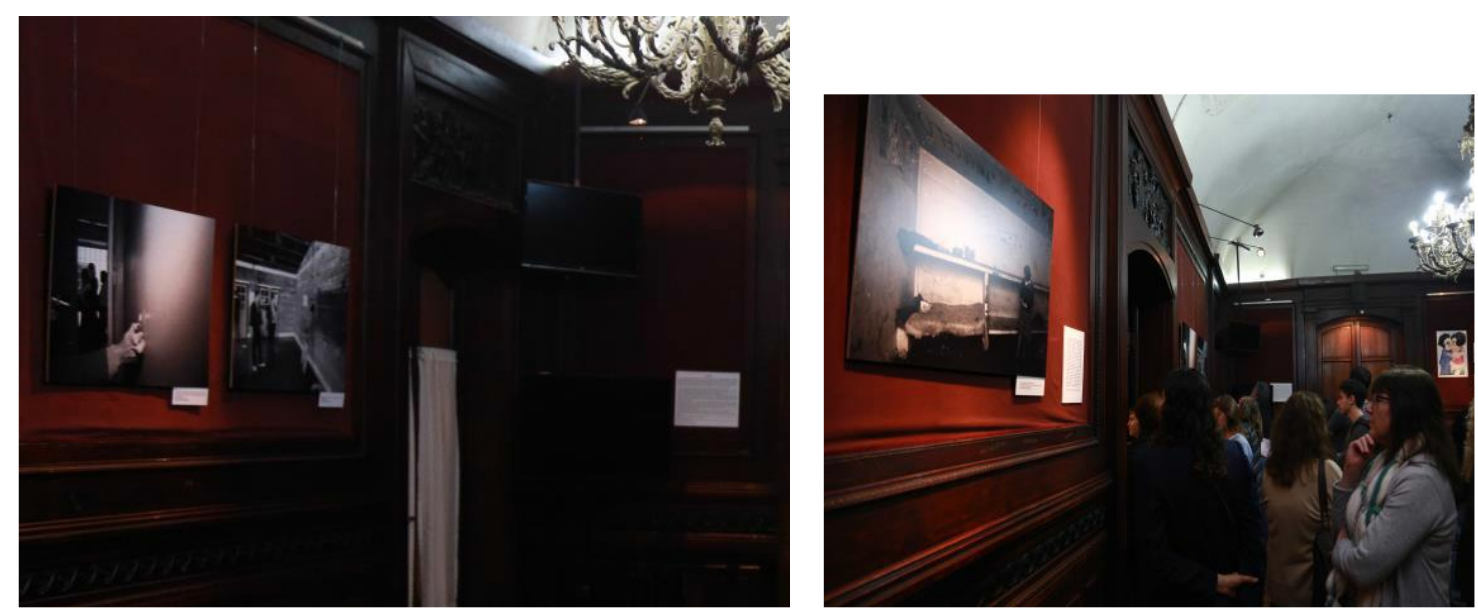

Imagen de la instalación: la vinculación entre Historia y Memoria y público contemplando imágenes

\section{Productos comunicacionales}

- Flyer: se diseño un flyer cuyo formato digital se viralizó en las redes sociales.

- Afiche: se elaboró un afiche impreso en papel que se colocó en diversas instituciones educativas y culturales en la Ciudad de Buenos Aires y alrededores. 


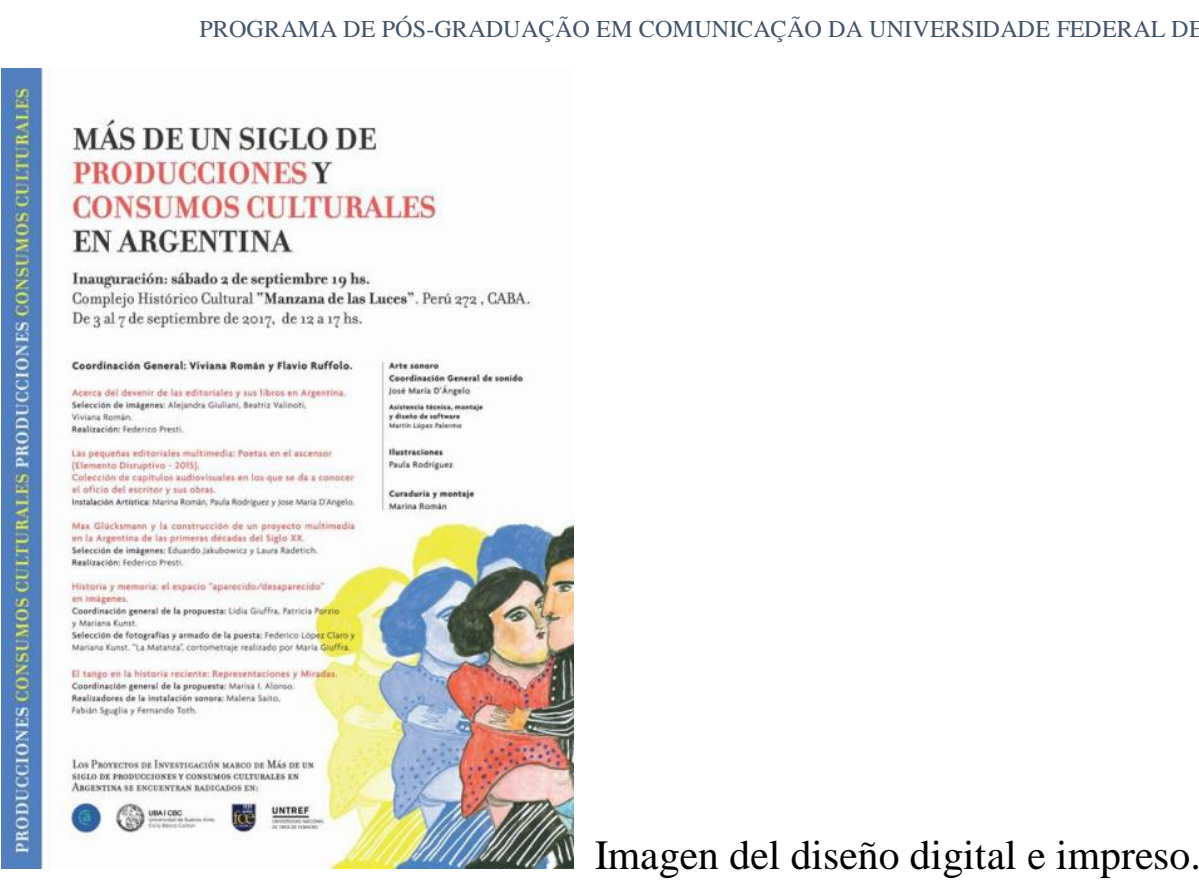

- Folleto: se diseño un folleto explicativo que se distribuyo durante los días que duró el evento
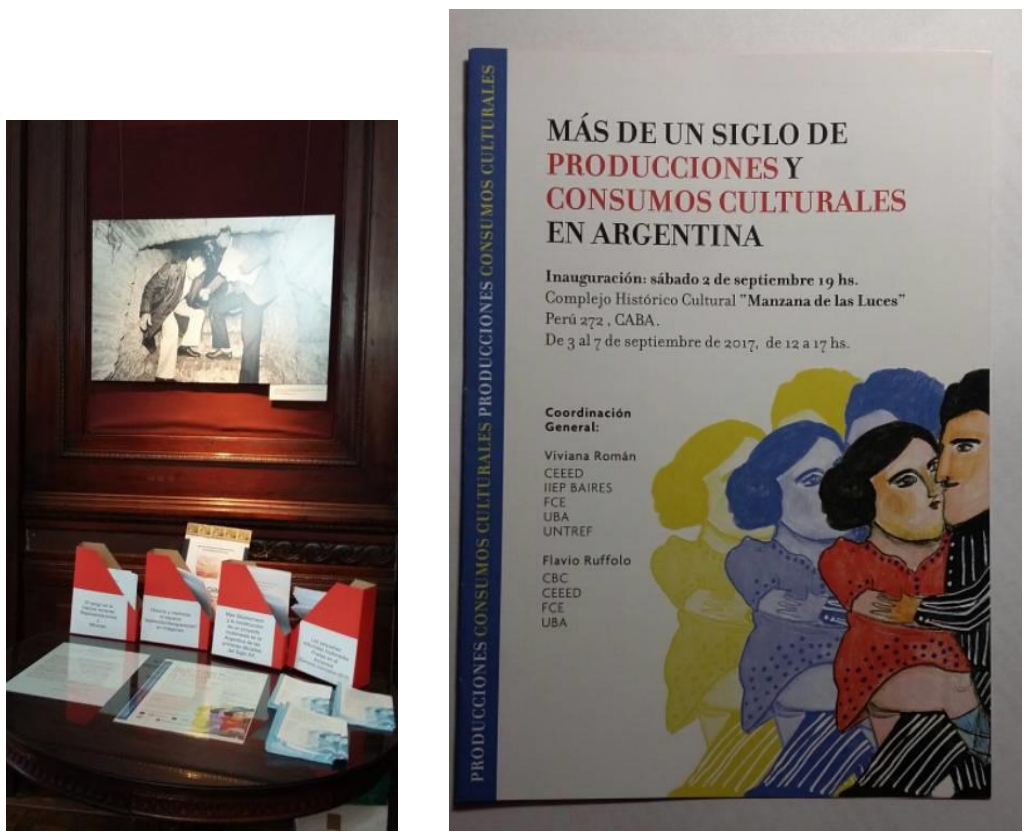

Folletería y reseñas de investigación impresas a disposición del público.

- Video: se realizó en el marco de la inauguración del evento un registro audiovisual como testimonio de lo realizado y como elemento de promoción para futuros eventos.

- Libro/publicación: se editó un libro titulado Más de un siglo de producciones y consumos culturales en la Argentina a través de una de las pequeñas editoriales estudiadas, en el mismo se analiza de diferentes maneras los contenidos que conforman en formato visual, audiovisual y sonoro la instalación. Así, relata los orígenes históricos de la instalación artística y del arte 
sonoro, en tanto prácticas artísticas; recorre el devenir de las editoriales y sus libros en el país, analiza la conformación de un multimedio a principios del siglo XX; reflexiona desde una lectura socio-histórica las representaciones sobre el concepto de espacio aparecido/desaparecido en imágenes en referencia a los acontecimientos vividos durante la última dictadura militar en la Argentina y por último, se presenta un ejemplo de reapropiación del tango por distintos actores sociales en relación a la patrimonialización que se hacen desde agencias públicas, convirtiéndolo en un elemento de referencia identitaria y mercancía cultural.

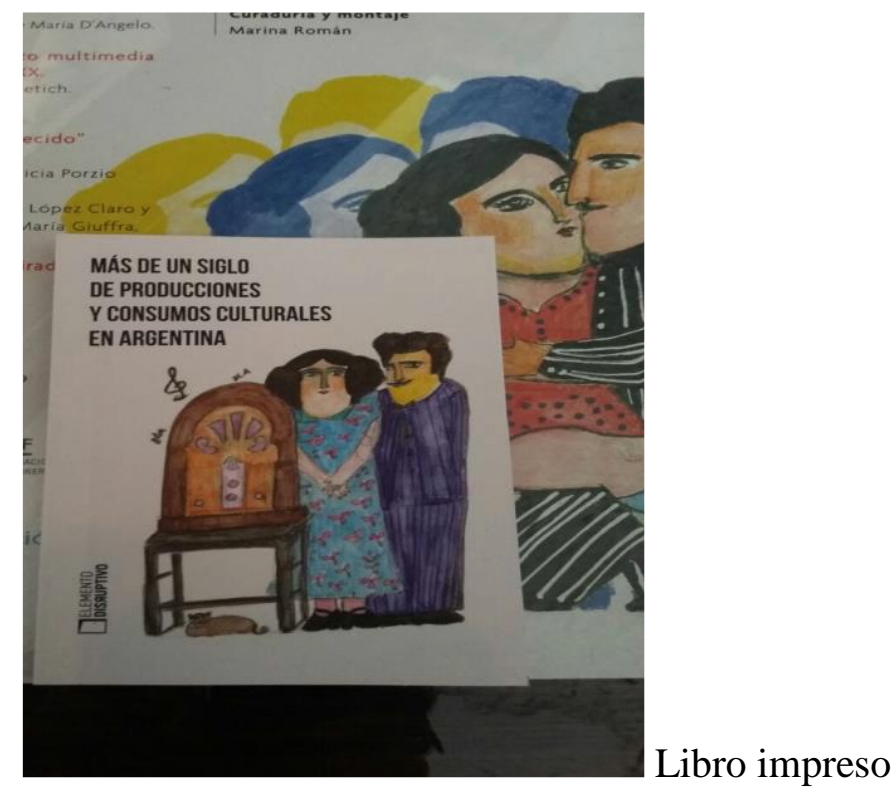

El conjunto de estas acciones fue fruto del cruce de diversas disciplinas que tuvo como eje las producciones y los consumos culturales en la Argentina, desde diversos productos/formatos se logró en un mismo espacio y tiempo articular en una instalación artística, que tal como se desarrollo, funcionó como dispositivo comunicacional dando lugar a un intercambio de saberes y experiencias en donde el público participante interactúo con cada uno estos elementos recreando y generando nuevos significados que se expresan en la posibilidad de adquirir nuevos conocimientos y reinterpretarlos a la luz de la información y los contenidos que los investigadores mostraron en sus diversos modos de presentación.

Esto da cuenta del principal objetivo que tuvo la instalación que fue la transferencia de conocimientos a través de recursos tecnológicos y artísticos que usualmente no se utilizan para la comunicación de las investigaciones en este tipo de saberes.

En este sentido, las distintas producciones fueron la materia significante en la que se expresaron los conocimientos producidos en torno a las elaboraciones y consumos culturales de bienes culturales construyendo un espacio comunicacional de intercambio y de producción 
de nuevos sentidos sociales cuyos alcances no son mensurable pero si perceptibles. Esto se puso en evidencia en la convocatoria y en la circulación de público participante durante el tiempo que duró el evento.

Arte y tecnología expuestos en un espacio público permitió la democratización del alcance del saber producido en un público amplio y variado.

\section{REFLEXIONES FINALES}

Transferir conocimientos académicos en un formato artístico, expresivo y comunicacional es sin duda un modo de democratizar el acceso a dichos conocimientos y mucho más significativo aún cuando se trata de seguir pensando diferentes aspectos de la historia social, económica y cultural de la Argentina. De este modo, la instalación permitió por sus propias características, desplazarse física y virtualmente a diferentes espacios para promover nuevos sentidos y seguir recreando significados sociales.

Los desplazamientos presentes de las prácticas artísticas hacia nuevos contextos de actuación, que se perciben en la actualidad, permiten insertarse a las distintas artes en los medios de comunicación, en espacios urbanos, en museos de diferentes disciplinas, redes digitales y diversas formas de participación social en donde la fusión estética es una mediación comunicacional para oír nuevas voces, ver otros modos de expresión e interactuar con múltiples discursos.

En esta experiencia en particular, el desafío fue por parte del equipo de investigadores construir contenidos de divulgación de sus propios trabajos académicos en formatos visuales, audiovisuales, gráficos y sonoros los cuales convivieron armónicamente en un espacio que articuló estéticamente los diferentes elementos presentes. Esto facilitó el acercamiento a los diversos públicos de contenidos y perspectivas no habituales en los consumos masivos de medios y redes tecnológicas.

El público se apropio de la propuesta, contemplo las imágenes ilustradas, se detuvo a mirar los videos referentes a la historia de las industrias editoriales y del primer empresario multimedia en nuestro país. Se acercó a la escenificación de un ascensor sorprendiéndose por los sonidos y poesías recitadas que se escuchaban cuando se aproximaban a dicho espacio. También percibían con mucha atención el corto audiovisual y las fotografías sobre los acontecimientos vividos en la Argentina durante la última dictadura militar en la construcción de la memoria visual y colectiva; asimismo se detenían y esperaban su turno en el rincón del 
tango para colocarse los auriculares conectados a un objeto armado con un viejo toca disco de marca conocido como "winco", en el que podían escuchar relatos de la historia del tango y canciones de sus principales músicos como signo identitario de la cultura local.

Por último, había folletería y reseñas de las investigaciones impresas para leerlas en el lugar o bien llevarlas.

Esta instalación artística fue un producto cultural y un consumo cultural que facilitó la divulgación y la transferencia de conocimientos en un espacio de interacción social, de construcción de sentidos, de enriquecimiento de miradas y nuevas reflexiones para la continuidad del análisis de ciertos tópicos de la historia de la Argentina.

\section{BIBLIOGRAFÍA}

Alonso, Marisa. (2017). Breve crónica de la instalación en la Manzana de las Luces. En Boletín de estudios sobre Activos Culturales- $\mathrm{N}^{\circ}$ 8. Buenos Aires.

Blanch González, Elena. (2009). I Procesos fundamentales de acción sobre la materia. En Procedimientos y materiales en la obra escultórica. Madrid. Editorial Akal.

Giuffra, Lidia. Kunst, Mariana. Porzio, Patricia. López Claro, Federico. (2017) Semblanza. "La Instalación”. Todo un reto. Más de un Siglo de producciones y consumos culturales en la Argentina. En Boletín de estudios sobre Activos Culturales- $\mathrm{N}^{\circ}$ 8. Buenos Aires.

Meunier, Jean Pierre. (2010) Dispositivo y Teorías de la comunicación: dos conceptos en relación de codeterminación. Bélgica. GReMS, Departement de Communication. Université Catholique de Louvain.

O’Sullivan, T. Hartley, J. Saunders, D. Montgomery, M. Fiske, J. (1995) Conceptos clave en comunicación y estudios culturales. Buenos Aires. Amorrortu.

Román, Viviana. Ruffolo, Flavio. (2017). Introducción. En Más de un Siglo de producciones y consumos culturales en la Argentina. Buenos Aires. Elemento disrruptivo.

Santana, Raúl. (2006). Catálogo Arte y política en los '60. Curador Alberto Guiduci. Palais de Glace. Buenos Aires. Fundación Banco Ciudad.

Valesini, Silvina. (2012) La instalación como dispositivo expositivo y comunicacional. El caso Misión/Misiones (como construir Catedrales) de Cildo Meireles en la I Bienal del Mercosur. La Plata. Facultad de Bellas Artes. Universidad Nacional de La Plata.

Original recebido em: 28 de março de 2019

Aceito para publicação em: 12 de maio de 2019

\section{(2) $(0 \Theta 0$}

Esta obra está licenciado com uma Licença 


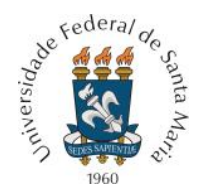

PROGRAMA DE PÓS-GRADUAÇÃO EM COMUNICAÇÃO DA UNIVERSIDADE FEDERAL DE SANTA MARIA

Creative Commons Atribuição-NãoComercial-CompartilhaIgual 4.0 Internacional 